\title{
Study of Modeling of Hybrid Energy System for Optimum Power Extraction from the System to the Grid
}

\author{
Ashish Srivastava \\ M. Tech Scholar \\ Technocrats Institute of Technology \\ Bhopal, M.P, India \\ ashishee09@gmail.com
}

\author{
Dr. M S Dash \\ Associate Professor \\ Technocrats Institute of Technology \\ Bhopal. M.P, India \\ malaya_rec@rediffmail.com
}

\begin{abstract}
With the growing demand of electricity, deployment of micro grid is becoming an attractive option to meet the energy demands. At present, large-scale wind/solar hybrid system is of great potential for development. The large-scale wind/solar hybrid system is of higher reliability compared with wind power generation alone and solar power generation alone However, a grid-connected micro grid suffers from critical stability problems during a power grid failure. For stable operation of the micro grid during a grid failure. In this paper, the transition stability of the micro grid is examined during a power failure.

Keywords: Renewable Energy system, PV Array, Wind System, MPPT Charge Controller, DC/DC Converter, Controlled Inverter, Grid System
\end{abstract}

\section{INTRODUCTION}

Energy incorporates a very important role for the development of a nation and it's to be preserved in a very most effective manner. Energy is that the ultimate issue accountable for each industrial and agricultural development. The new technologies that are developed to provide energy within the most environmental friendly manner and conservation of energy resources in most economical means has equal importance. The utilization of renewable energy technology to satisfy the energy demands has been steady increasing for the past few years. Import of petroleum products constitutes a serious drain on our foreign exchange reserve. Renewable energy sources are considered to be the higher choice to meet these challenges. The necessary drawbacks related to renewable energy systems are their inability to ensure reliability and their intermittent nature. A serious challenge of grid integration an increasing number of renewable-

Energy-based distributed generators is featured whereas making certain stability, voltage regulation, and power quality [1].

\subsection{Hybrid System}

The large-scale wind/solar hybrid system is connected to grid via a booster station. The system consists of wind power system and photovoltaic system. In order to improve the transient voltage stability of the large-scale wind/solar hybrid system, reactive power compensation device SVC (Static Var Compensator, SVC) is connected to grid.

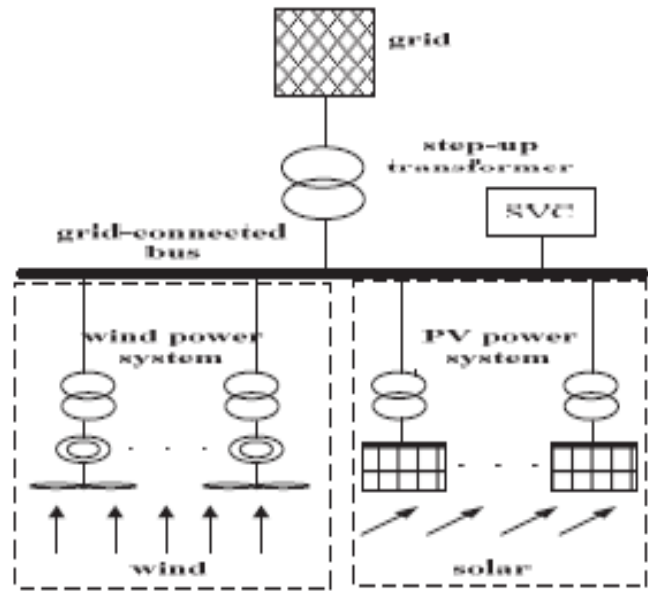

Fig 1.1: Diagram of wind/solar hybrid system

The wind power generation system consists of DFIG wind turbine and boost transformer. The output of the wind power generation system is limited by wind speed, dispatching commands and photovoltaic power. The photovoltaic power generation system consists of photovoltaic arrays, gridconnected inverter and boost transformer. The output of the photovoltaic power generation system is limited by light intensity, temperature, dispatching commands and the output of wind power generation system. It is worth noting that, SVC provides or absorbs reactive power by detecting the voltage at the parallel point with grid when the external fault occurs in grid. With the help of SVC, the voltage of grid connected bus is maintained.

1.2 Modeling of PV Array 
The photovoltaic system connected to the grid is a more reliable solution to increase the demand for energy. The network connection of a photovoltaic power generation system has the advantage of more efficient use of the generated energy. The PV systems are connected to the grid via the inverter, which converts the DC energy generated by the PV modules into alternating current. The inverter technology is very important to ensure a reliable connection and safe operation of the photovoltaic network.[2]

Again, the power generated by a single module is not enough to meet the performance requirements for most practical applications. Photovoltaic modules these inverters convert the output from DC to AC and use it for motors, lighting, and other loads. Modules are connected in series for higher voltage, then in parallel to meet current specifications. A PV module consists of several cells of the NS series, while the cells of the photovoltaic panels are connected in series and in parallel, as shown in figure 1.2 wherever the arrangement defines the maximum output voltage $\mathrm{V}_{\mathrm{M}}$ and maximum output current $\mathrm{I}_{\mathrm{M}}$.

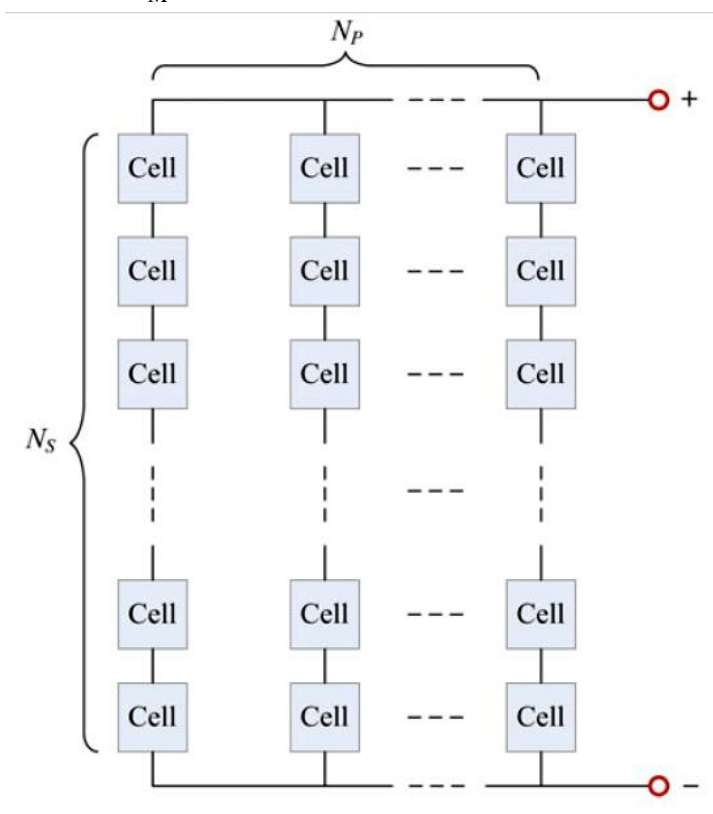

Fig 1.2: Electrical Connection Diagram of a PV Array

At a certain current, the output current and operating voltages of a module are determined by the properties of the load. To determine the properties of the PV module, power vs. Voltage (P-V), and current vs. Voltage (I-V) curves must be constructed. The Typical P-V and I-V characteristics of a PV cell are shown in Fig 1.3.

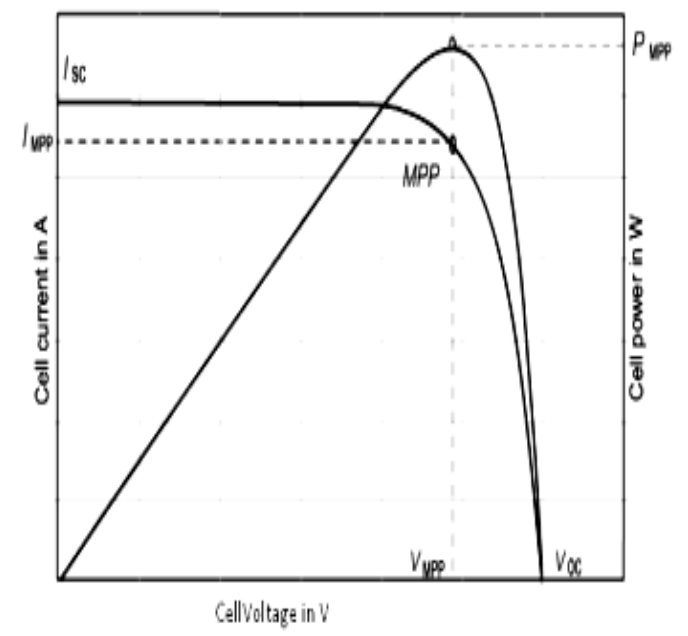

Fig 1.3: P-V, I-V Curve of the PV Cell at a Given Temperature and Irradiation

\subsection{Wind Energy}

The kinetic energy of the wind causes the wind turbine blades to rotate. This leads to a rotation of the generator shaft, which is connected to the rotor blades. The generator converts the mechanical energy of the rotating shaft into electrical energy. It is optional to connect the slow shaft of the rotor blades with a reducer to the high speed shaft of the generator.

In some cases, transmissions are not desirable because they are expensive, cumbersome and heavy. A multi polar generator is an alternative possibility of a gearless system.

The power cable transfers electricity to a transformer. The transformer increases the low voltages of the generator to the level of distribution or sub-transmission of the connected system

Power Control System

To throw constant power into the grid, the capacitor voltage must be maintained constant. As the power generated on DC bus increases capacitor gets over-charged.

Voltage of capacitor is compared with a reference value and using PID control system the power angle of inverter is changed to control the power flow into the grid (fig. 1.4).

The capacitor voltage is maintained at such a value so as to reduce reactive power demand of inverter. 


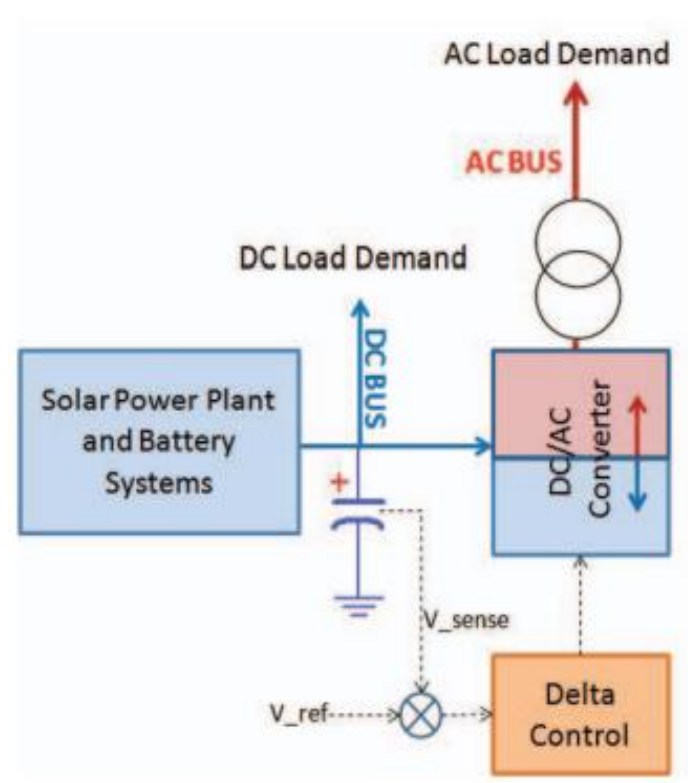

Fig. 1.4 : Control System for Power flow

Discrete PID control [3] is applied for active and reactive power control. PID control is implemented to maintain the voltage of capacitor same as that of reference voltage. The power transfer from DC side to AC side is governed by phase angle (power angle), given by equation,

Pactive $=E V \sin (\delta) X[6]$.

As the Capacitor voltage increases phase angle is increased to alter the power flow from Inverter to Grid.

1.4 DFIG

DFIG modeling is performed in detail with its control structure in order to identify and focus on some important parameters such as speed, mechanical and electrical torque, DC voltage and active power at steady state. The improvement in adding commands to the system can be seen by comparing parameters with and without commands. Variable speed operation is identified and wind speed noise suppression is also performed. The correlation analysis between electric torque and real power has been demonstrated. The efficiency of the proposed model is also obtained by comparing this model with the model data of the integrated model of MATLAB / SIMULINK.

Generator model Modeling of induction machines has been performed in several ways in the literature. Among them, the "parking model", which is a two-axis model or a d-q representation, was chosen here to model DFIG. A fifth-order fleet model is simulated in the Matlab and Simulink environments [7, 9].

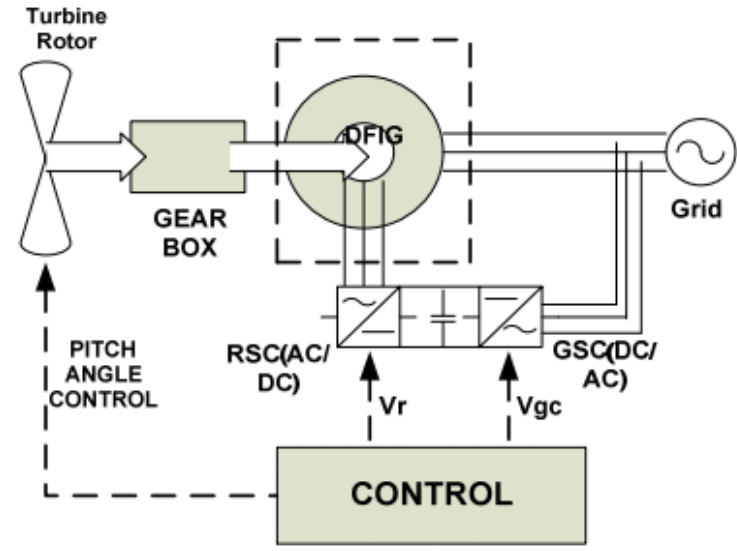

Fig. 1.5 Block diagram of DFIG system

The transformation from the real static $\mathrm{ABC}$ axis to the imaginary, but rotating $d-q$ axis facilitates modeling of the induction generator in simulation work. Depending on the speed of the frame of reference dq, we can distinguish three categories: stationary rotary frame of reference (where the speed is stationary, $\omega=0$ ), the synchronous rotary frame of reference (where the speed is the same as the synchronous speed $\omega=\omega b$ ) and frame rotor (where the speed of rotation is same as rotor speed, $\omega=\omega r$ ).

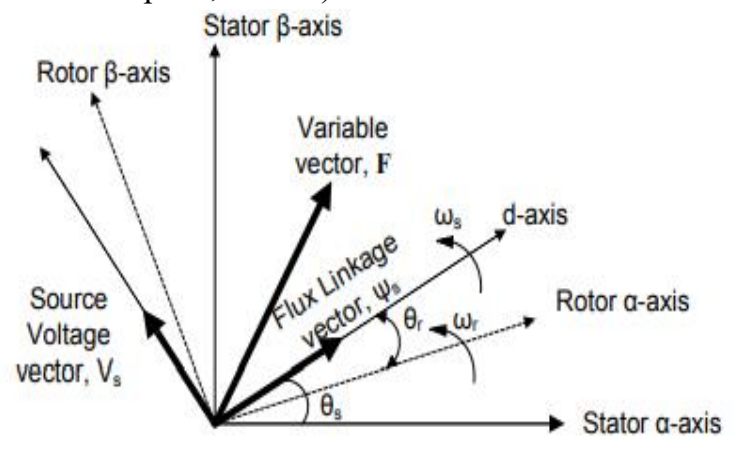

Fig.1.6 Phasor representation of vector diagram.

\section{LITERATURE REVIEW}

[1] The purpose of this document is to update the current state of the design, operation, and control requirements of stand-alone photovoltaic-solar-wind hybrid energy systems with a conventional backup source, e.g. H. Diesel or mains, check. This paper also highlights future developments that have the potential to increase the economic attractiveness of such systems and their acceptance by users.

[2] A hybrid wind-photovoltaic-diesel propulsion system has been developed for a village in Saudi Arabia, currently powered by a diesel power plant with eight diesel generating sets of $1,120 \mathrm{~kW}$ each. The study found that a hybrid windphotovoltaic-diesel propulsion system with $35 \%$ renewable energy (26\% wind and $9 \%$ solar photovoltaic) is the viable system with energy costs of USD $0.212 / \mathrm{kWh}$. The proposed system consisted of 3 wind turbines of $600 \mathrm{~kW}$ each, 
photovoltaic modules of $1000 \mathrm{~kW}$ and four diesel generators with a nominal power of $1120 \mathrm{~kW}$ each. The system was able to cover the energy needs (primary AC load of 17,043.4 $\mathrm{MWh}$ / year) of the village with an energy surplus of $4.1 \%$.

[3] This paper proposes a new operation and control strategy for a renewable hybrid energy system for autonomous operation. The proposed hybrid system includes a wind turbine, a fuel cell, an electrolyze, a battery storage system and a range of loads. The overall control strategy is based on a two-tier structure. The highest level is the energy management and power control system. Depending on the wind and load conditions, this system generates dynamic operational reference points for the individual subsystems at a low level.

[5] The objective of this thesis is the study and implementation of mixed random modulation techniques to reduce the magneto-acoustic noise in asynchronous railway traction motors powered by inverters. The current harmonics generated by the PWM modulation increase the magnetic noise of the motor. The switching frequency for this type of application is relatively low (generally 1 to $2 \mathrm{kHz}$ ) and is in the audible band.

\section{METHODOLOGY}

\subsection{Modeling of PV Arrays}

The cells are made in mono crystalline or polycrystalline structure relying to the purity of semiconductor [5-7]. The polycrystalline cells that give limited potency around 13$14 \%$ are less economical comparing to the mono crystalline that the efficiency will increase up to 20 .

This circuit shown in Fig 3.1 includes a photocurrent source, a diode, and serial and shunt resistors that are referred to as one-diode or five-parameter model [8]. The calculations of the one-diode model are depended to the output current:

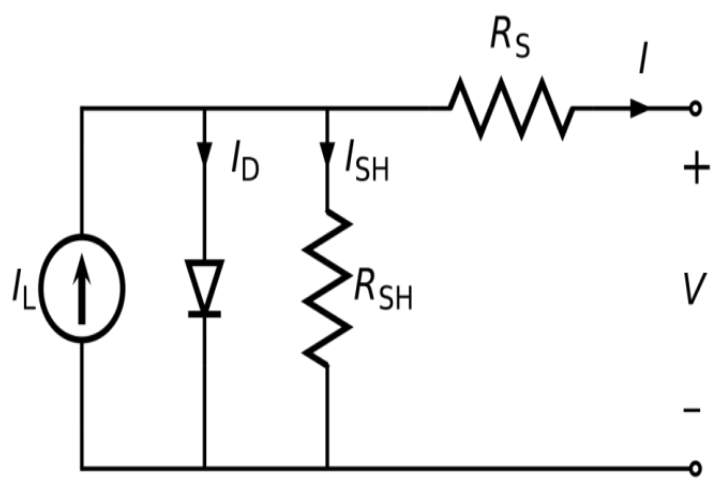

Fig 3.1: Electrical Equivalent of PV Cell

$$
I_{o}=I_{P V}-I_{D}(V)-I_{S H}(V)
$$

Where (V) shows the dependency of diode current and resistor current to the terminal voltage whereas they're independent from irradiation value.

\subsection{Modeling of Wind System}

The wind turbine (WT) converts wind energy to mechanical energy. The power output of a wind turbine can be expressed as shown in Figure 3.2 and the aerodynamic torque is given by:

$$
\begin{gathered}
P_{w}=0.5 C_{p} \rho A V_{w}^{3} \\
T_{w}=\frac{P_{w}}{\omega_{W}}
\end{gathered}
$$

Where $\mathrm{P}_{\mathrm{W}}=$ Wind Turbine Power (in Watt)

$\mathrm{P}=$ Air Density $\left(\right.$ in $\left.\mathrm{Kg} / \mathrm{m}^{3}\right)$

$A=$ Rotor Area $\left(\right.$ in $\left.\mathrm{m}^{2}\right)$

$\mathrm{V}_{\mathrm{W}}=$ Velocity of wind (in $\mathrm{m} / \mathrm{sec}$ )

$\boldsymbol{\omega}=$ Turbine rotor speed $($ in $\mathrm{rad} / \mathrm{sec}) /$

$\mathrm{C}_{\mathrm{P}}=$ Power Co-efficient, It is the function of tip speed and blade pitch angle.

Mathematical modeling of rsc and gsc

for a doubly-fed induction generator based wind generation system, the DFIG's stator output active and reactive power is controlled through RSC, whereas the GSC controls the common dc-link voltage.

3.3 Control mechanism

3.3.1 Current mode control is better than the single voltage control as it improves the dynamic behavior of power converter as the current changes instantaneous in the event of source change.

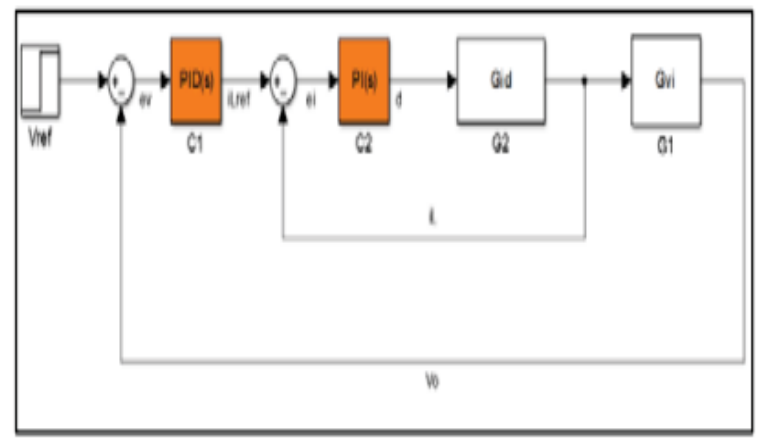

Fig 3.2: Cascade current control diagram

\subsubsection{Fuzzy Control}

The fuzzy system in this paper has two inputs. The first input is the error, $\mathrm{E}[\mathrm{k}]$ which is the difference between reference DC bus voltage and the measured DC bus voltage. The second input is the change in error, $\mathrm{CE}$ which is the derivative (dE/dt) of error.[11]

$$
\begin{aligned}
& E[k]=V_{d c_{\text {rref }[k]}}-V_{d c_{-} \text {mea }[k]} \\
& C E[k]=E[k]-E[k-1]
\end{aligned}
$$

where, Vdc_ref and Vdc_mea are the reference and measured voltage at $\mathrm{k}$ th sampling time. 
The output of the fuzzy controller is the change of current which then to be output to the current controller of the battery and supercapacitor as illustrated in Fig 8

$$
I_{d c_{-} r e f}=I_{d c_{-} r e f[k-1]}+\Delta I \text {. }
$$

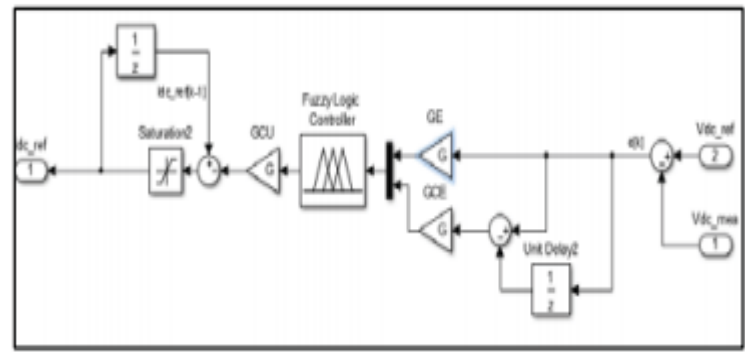

Fig 3.3: Fuzzy control structure

\subsubsection{GA-PID}

GA-PID is used to tune the PID parameter directly using the electric model build in MATLAB SIMULINK power system with GA toolbox to take in account the system dynamics.

Genetic Algorithm is a search technique used in finding exact or best possible solutions to optimization and search problems [14]. Over the last decades, GA has been adapted as search and optimization in wide areas of application such as engineering, economic and science $[11,12]$.

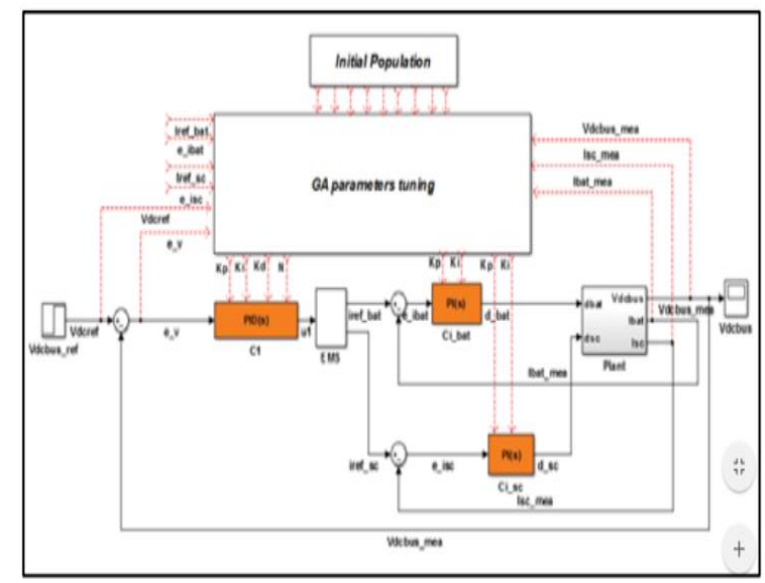

Fig 3.4 Block diagram of GA-PID Tuning on 3 controllers

\subsection{Static Var Compensator}

The SVC is similar to a synchronous compensator in that it is used to supply or absorb reactive power but without rotating part. The SVC provides rapid and fine adjustment of voltage, which is as to maintain or control specific power system variables.

It can be operated in both inductive and capacitive modes. Note that SVC current is considered positive when SVC susceptance is inductive. The configuration and equivalent of SVC are shown in Fig. 3.5

The steady state control characteristic of SVC is shown in Fig. 3.6

The voltage UREF is the voltage at the terminals of the SVC when it is neither absorbing nor generating any reactive power.
The SVC damping controller structure is shown in Fig. 3.7
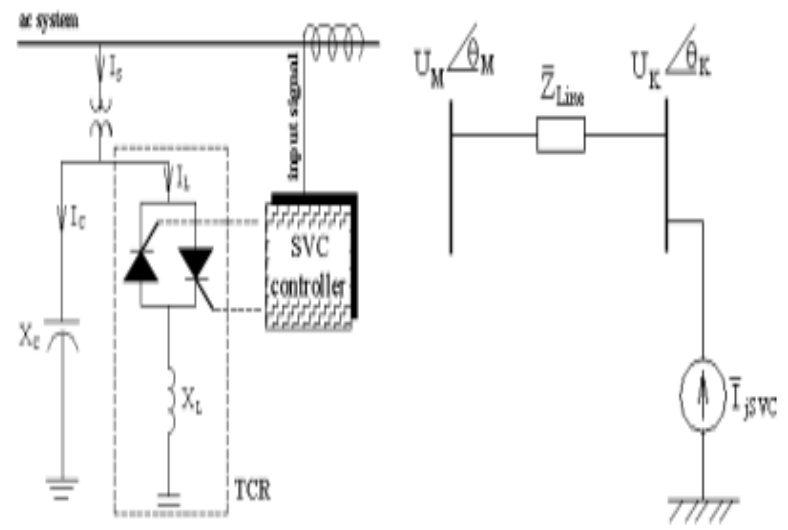

Fig.3.5. SVC configuration and equivalent model

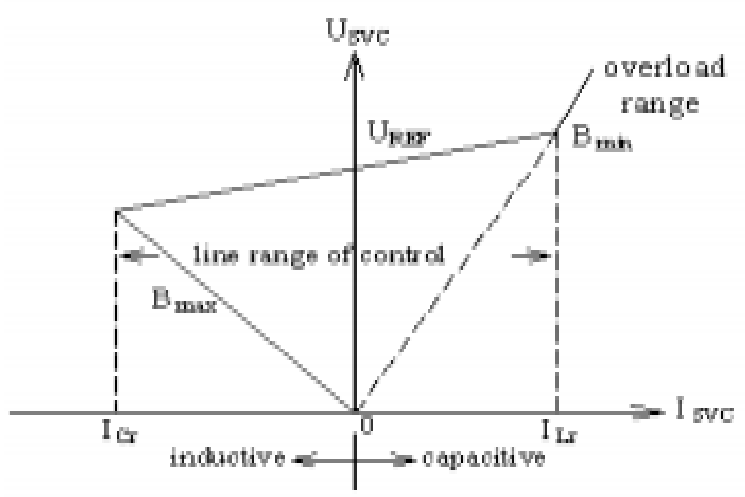

Fig. 3.6. Terminal characteristic of the SVC

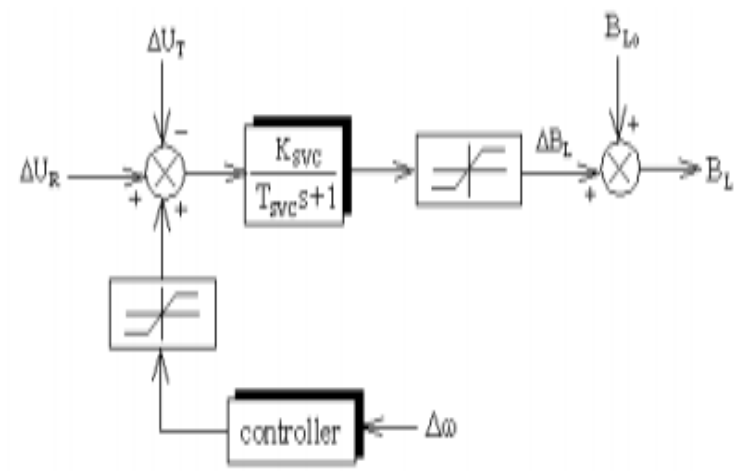

Fig. 3.7. General form of the SVC control system

\section{CONCLUSION}

Renewable energy sources also called non-conventional type of energy are continuously replenished by natural processes. Hybrid systems are the right solution for a clean energy production. Hybridizing solar and wind power sources provide a realistic form of power generation. In addition, a battery module is added as an energy storage system in case of overvoltage and/or as a backup device in case of need for recharging. MPPT control is performed for PV and wind so that maximum power is followed and the system works more reliably and efficiently. This system has lower operating 
costs and is used in remote power generation, constant and variable speed power conversion systems, and rural electrification. MATLAB/ SIMULINK software can be used to model the PV panel, wind turbine, DC-DC converters, MPPT controller and proposed hybrid system.

The models of hybrid renewable energy systems are integrated with the grid through Voltage Source Inverter. The system can be further improved by providing a compensating device with efficient modeling to balance the reactive power.

\section{REFERENCES}

[1] K. Yamashita, H. Renner, S. M. Villanueva, G. Lammert, P. Aristidou, J. C. Martins, L. -Z. Zhu, L. D. P. Ospina, and T. V. Cutsem, "Industrial recommendation of modeling of inverter-based generators for power system dynamic studies with focus on photovoltaic," IEEE Power and Energy Technology Systems Journal, vol. 5, no. 1, pp. 1-10, Mar. 2018.

[2] A. M. Khalil and R. Iravani, "Enhanced generic nonlinear and linearized models of wind power plants," IEEE Transactions on Power Systems, vol. 32, no. 5, pp. 3968-3980, Sep. 2017.

[3] G. Shahgholian, "Power system stabilizer application for load frequency control in hydro-electric power plant", Engineering Mathematics, 2, No. 1, pp. 21-30, Feb. 2017.

[4] T. Fetouh, M.S. Zaky, "New approach to design SVC-based stabilizer using genetic algorithm and rough set theory", IET Gen., Trans. and Dist., 11, No. 2, pp. 372-382, Jan. 2017.

[5] O. G * oksu, M. Altin, J. Fortmann, and P. Sørensen, "Field validation of " IEC 61400-27-1 wind generation Type 3 model with plant power factor controller," IEEE Transactions on Energy Conversion, vol. 31, no. 3, pp. 1170-1178, Sep. 2016.

[6] T. Salmi, M. Bouzguenda, A. Gastl, Ahmed Masmoudi, "MATLAB/Simulink Based Modelling of Solar Photovoltaic Cell", International Journal of Renewable Energy Research, vol. 2, no. 2, 2012.

[7] Accardo, L, Fioretto, M, Giannini, G \& Marino, P 2006, 'Techniques of PWM space vector modulation for the reduction of magnetic acoustic noise in traction motors', International symposium on Power Electronics, Electrical drives, Automation and Motion, Taormina, pp. 1084-1089.

[8] F. Liu, S. Duan, F. Liu, B. Liu, Y. Kang, "A Variable Step Size INC MPPT Method for PV Systems", IEEE Transaction on industrial Electronics, vol. 55, no. 7, pp. 2622-2628, July 2008.

[9] W. Xiao, N. Ozog, W.G. Dunford, "Topology Study of Photovoltaic Interface for Maximum Power Point Tracking", IEEE Transactions on industrial electronics, vol. 54, no. 3, pp. 1696-1704, June 2007.

[10] F. Ding, P. Li, B. Huang, F. Gao, C. Ding, W. Chengshan, "Modeling and Simulation of Grid-connected Hybrid Photovoltaic/Battery Distributed Generation System", 2010 China International Conference on Electricity Distribution, pp. 1-10, Sept 2010.

[11] H. Sefidgar, S. A. Gholamian, "Fuzzy logic control of wind turbine system connection to PM synchronous generator for maximum power point tracking", Int. J. Intelligent Syst. and Appl., vol. 07, 2014.

[12] S. Singh, L. Mathew, S.L. Shimi, "Design and simulation of intelligent control MPPT technique for PV module using MATLAB/ SIMSCAPE", Int. J. of Adv. Res. in Elect. Electro. and Instr. Eng., vol. 2, pp. 2278-8875, 2013.

[13] N. A. Kamarzaman, C. W. Tan, "A comprehensive review of maximum power point tracking algorithms for photovoltaic systems", Renewable and Sustainable Energy Reviews, vol. 37, pp. 585-598, 2014.
[14] A. Anurag, S. Bal, S. Sourav, M. Nanda, "A comprehensible review of maximum power point tracking techniques for photovoltaic systems", Int. J. of sustainable energy, vol. 35, pp. 478-501, 2016.

[15] M.-F. Tsai, C.-S. Tseng, Y.-H. Hung, "A novel MPPT control design for wind-turbine generation systems using neural network compensator", IECON 2012-38th Annual Conf. on IEEE Indust. Elect. Soc., pp. 3521-3526, 2012.

[16] M. A. Abdullah, A. H. M. Yatim, C. Wei Tan, "A study of maximum power point tracking algorithms for wind energy system", IEEE First Conf. on Clean Energy and Tech. CET, pp. 321-326, 2011.

[17] Y. Xia, K. H. Ahmed, B. W. Williams, "A new maximum power point tracking technique for permanent magnet synchronous generator based wind energy conversion system", IEEE Trans. on power electronics, vol. 26, pp. 3609-3620, 2011.

[18] E. M. Natsheh, A. Albarbar, "Hybrid power systems energy controller based on neural network and fuzzy logic", Smart Grid and Renewable Energy, vol. 4, pp. 187-197, 2013. 